УДК $338.48(470.12)$

\title{
ИННОВАЦИОННАЯ ДЕЯТЕЛЬНОСТЬ КАК СРЕДСТВО УКРЕПЛЕНИЯ ЭКОНОМИЧЕСКОГО ПОТЕНЦИАЛА СФЕРЫ ТУРИЗМА В РЕГИОНЕ
}

\author{
(C) 2012 г. Ю. Ю. Нвеи
}

\section{Институт проблем управления РАН, г. Москва}

В статье рассмотрены проблемы развития инновационной деятельности как средства укрепления экономического потенциила сферы туризма. Рассмотрены классификационные признаки инноваций в туризме. Проведен сравнительный анализ процессов, входящих в состав инновационной деятельности в туризме. Представлены основные направления инновационной деятельности в туризме в зависимости от того к какому процессу они относятся, в зависимости от того к какому элементу они относятся.

Ключевые слова: инноващия; инновачионная деятельность; туризм; туристическая инноващия.

The paper is devoted to problems of innovation activities' improvement as of an instrument for strengthening the economic potential of the tourism branch. Some classification attributes for the innovations in tourism are considered. A comparative analysis of processes that the innovation activity in tourism consists of is also held. The paper contains a list of the main directions for the innovation activities in tourism, depending on a process they concern, and an element they belong to.

Key words: innovation; innovation activity; tourism; tourism innovation.

Региональная специфика сферы туризма заключается в особом характере взаимоотношений на региональном уровне между туристическим кластером и местным управлением и самоуправлением, изменяющимися под воздействием факторов как глобальной, так и локальной природы, особенно учитывая национальную составляющую. Указанная национальная составляющая на региональном уровне проявляет себя по-разному в каждом субъекте управления. Поэтому проблему инновационного развития сферы туризма необходимо рассматривать в контексте социальноэкономического развития каждого конкретного региона, даже при кажущейся глобализации. При этом регион с позиций интересов туристического кластера рассматривается, во-первых, как пространственно (территориально) определенная территория, на которой располагаются объекты туристского интереса и инфраструктура, обслуживаю- щая туристов (в понимании Федерального Закона Российской Федерации «Об основах туристической деятельности» от 24 ноября 1999 года с поправками и изменениями) и не ограниченная административными границами. Во-вторых, как целевой интегрированный ресурс для устойчивого функционирования и развития туризма, являющийся основой для формирования и развития и реализации туристских продуктов. В-третьих, необходимо определить указанные взаимоотношения как реализуемую совокупность туристско-рекреационных особых экономических зон социально-экономическое территориальное образование с наличием управляющей компании или без таковой. Создание управляющих компаний вводится федеральными властями при попытке реализации определенных законодательством инициатив, таких как внесение изменений в Федеральный закон РФ от 22 июля 2005 года №116-Ф3 «Об особых 
экономических зонах в Российской Федерации», предлагаемых Проектом №549129-5, внесенным на рассмотрение депутатом Государственной Думы Федерального Собрания Российской Федерации С. С. Журовой.

Комплексное решение целого ряда экономических, организационных, экологических, социальных, правовых и других вопросов должно способствовать развитию сферы туризма в регионе при введении социальноэкономических зон путем увеличения вклада в экономику как на национальном, так и на региональном уровне. Необходимо отметить, что туризм сам по себе обладает синергетическим и мультипликативным эффектом и способен создать предпосылки для экономического подъема выбранных территорий путем не только увеличения занятости населения и развития интеркультурных взаимоотношений, что особенно важно при сегодняшних геополитических задачах страны, но и более полного удовлетворения потребностей потребителей.

Целью статьи является обоснование необходимости развития инновационной деятельности, как средства укрепления экономического потенциала сферы туризма в регионе.

В современных условиях инновационность является характерным признаком развития общества. В туристический бизнес этот аспект вносит особую значимость. Созданный туристический продукт нельзя оставлять неизменным, его нужно постоянно модернизировать. Растущие потребности граждан, которые становятся все более требовательными, обязывают к использованию современных достижений науки и техники, к внедрению новых технологий питания и обслуживания. Для эффективного ведения туристского бизнеса необходимо раскрыть сущность понятия «инновации в туризме» и определить основные направления инновационной деятельности в этой сфере.

Туризм как особый социально-экономический и культурный феномен возник относительно недавно и перерос путешествия и в количественном и качественном планах. В настоящее время путешествие является важным, но далеко не единственным, а зачастую и не главным элементом туризма [14].

Туристическая сфера в настоящее время представляет собой целую систему, вклю- чающую в себя разнообразные элементы. К ним относятся:

- туристский продукт - туристские услуги и туры;

- субъект туризма - органы управления туризмом, учебные, научные, проектные учреждения;

- участник туризма - потребитель (гражданин, пользующийся продуктами и услугами системы туризма);

- объект туризма - предприятия, предоставляющие услуги по размещению, питанию, транспортные предприятия, экскурсионное бюро, предприятия сферы досуга и развлечений и т. д.;

- организатор туризма - туристские предприятия по разработке, продвижению и реализации туристского продукта (туроператоры и турагенты).

Приведенный перечень является далеко не полным. По мере расширения и усложнения процессов организации туризма все новые отрасли и предприятия национальной экономики вовлекаются в туристское производство. Обслуживанием туристов занимаются предприятия торговли, банки, страховые компании. Косвенно формируют туристскую индустрию учреждения культуры, лечебные и медицинские учреждения, организации связи, общественный пассажирский транспорт и т. д.

Общепринятым является утверждение, что термин «инновация» в современном его понимании первым стал применять Й. Шумпетер, который подчеркивал, что инновация - это существенная смена функции производимого, состоящая в новом соединении и коммерциализации всех новых комбинаций, основанных на использовании новых материалов и компонентов, внедрении новых процессов, открытии новых рынков, внедрении новых организационных форм [17]. Но говоря о применении данного термина, необходимо отметить, что русскоязычные источники классифицируют термин «инновация» по-разному [1]. Необходимо также отметить: инновация должна пониматься во временном аспекте производственного цикла как товаров, так и услуг, а, следовательно, необходимо в дальнейших исследованиях более детально изучить этот вопрос, в том числе в сфере туризма. 
Характерной чертой всех рассмотренных трактовок понятия «инновация» является обязательное наличие элемента новизны. Во всех определениях инновация выступает в качестве явного фактора перемены, как результат инновационной деятельности, воплощенный в новом или усовершенствованном продукте, технологических процессах, новых услугах и новых подходах к удовлетворению социальных потребностей и приводящий к получению экономического эффекта.

Сфера инноваций не только охватывает практическое использование научно-технических разработок и изобретений, но и включает перемены в продукте, процессах, маркетинге, организации хозяйствующих субъектов различной отраслевой принадлежности.

К основным функциям инноваций можно отнести следующие:

- вовлечение в производство новых производительных сил, повышение производительности труда и эффективности производства, сокращение различного рода затрат;

- повышение уровня жизни каждого человека и общества в целом за счет разнообразия и качества производимой продукции и услуг, удовлетворения потребностей населения;

- приведение в соответствие структуры производства со структурой изменившихся потребностей, поддержание равновесия между спросом и предложением, между производством и потреблением;

— конечный результат применения творческих возможностей и знаний конкретной личности, человеческого интеллекта, что, в свою очередь, стимулирует дальнейший рост творческой деятельности.

Изучение тенденций и закономерностей комплексного освоения инноваций, планирование положительных результатов и управление ими - сложная методологическая проблема в сфере туризма, связанная, прежде всего, с классификацией нововведений. В качестве значимых для определения сути инноваций в туризме выделяют следующие классификационные признаки:

- источник идеи (потребности туристов, открытия, изобретения);

- вид инновации (инфраструктура туризма, турпродукт, способы и средства рас- пределения турпродукта/услуги, управление и т. д.);

- степень новизны (улучшающие, прорывные);

- широта воздействия, масштабность, связность (локальные, глобальные, системные);

- инвестиционное наполнение (некапиталоемкие, малокапиталоемкие, капиталоемкие).

Инновации в туризме следует рассматривать как системные мероприятия, имеющие качественную новизну и приводящие к позитивным сдвигам, обеспечивающим устойчивое функционирование и развитие отрасли в регионе. Так, идея создания и реализация туристских проектов, даже не приносящих вначале существенной прибыли, может дать толчок развитию туризма и, тем самым, активно способствовать созданию дополнительных рабочих мест и росту доходов населения.

Результатом туристской деятельности является продукт, который по разным причинам устаревает. На основе того, что потребитель туристских услуг потребляет некоторое количество продуктов или услуг, с одной стороны среди поставщиков туристских услуг появляется конкуренция. С другой стороны, поставщикам приходится кооперироваться между собой, когда потребитель нуждается в дополнительных услугах. В процессе кооперации и конкуренции возникает новый туристский продукт. В этот момент традиционный туризм преобразуется в инновационный.

Идея классифицирования туристкой деятельности по степени новаторства не нова. В одном из трудов Н. И. Лапина дается четкое разграничение классического и инновационного туризма [6].

Деление туризма на классический и инновационный предопределяет необходимость уточнения понятийного аппарата, отражающего особенности развития той или иной модели. В контексте настоящего исследования предложим понятия инновационной деятельности в туризме, традиционно рассматриваемые исследователями разных стран в различные временные периоды: инновационная деятельность, инновационный продукт.

Инновационная деятельность в туризме - это тесно связанные между собой процессы по формированию, реализации, про- 
Таблица 1

Трактовка процессов инновационной деятельности в туризме

\begin{tabular}{|c|c|c|}
\hline Процессы & Традиционный туризм & Инновационный туризм \\
\hline $\begin{array}{l}\text { Формирование } \\
\text { туристической } \\
\text { услуги }\end{array}$ & $\begin{array}{l}\text { Деятельность туроператора по } \\
\text { заключению и исполнению до- } \\
\text { говоров с третьими лицами, ока- } \\
\text { зывающими отдельные услуги, } \\
\text { входящие в туристский продукт } \\
\text { (гостиницы, перевозчики, эк- } \\
\text { скурсоводы (гиды) и другие). }\end{array}$ & \multirow{2}{*}{$\begin{array}{l}\text { Формирование туристического предло- } \\
\text { жения (услуги) в динамической поста- } \\
\text { новке в масштабе реального времени, } \\
\text { позволяющей по требованию потреби- } \\
\text { теля или агента, продающего услуги, } \\
\text { формировать различные комбинации } \\
\text { компонентов услуги. Новая информа- } \\
\text { ция, полученная в процессе решения } \\
\text { динамических задач, может существен- } \\
\text { но менять решение заказчика о включе- } \\
\text { нии тех или иных услуг в предложение. } \\
\text { Используя принципы динамической } \\
\text { компоновки формирования услуги и ее } \\
\text { инновационного продвижения, потре- } \\
\text { битель получает полностью реализа- } \\
\text { цию своих потребностей на основании } \\
\text { сформированного им запроса, без необ- } \\
\text { ходимости применения традиционных } \\
\text { маркетинговых инструментов. } \\
\text { Возможные варианты формирования } \\
\text { и продвижения - это е-туризм («элек- } \\
\text { тронный туризм»), е-путешествия, пэ- } \\
\text { кедж-туры. }\end{array}$} \\
\hline $\begin{array}{l}\text { Продвижение } \\
\text { туристической } \\
\text { услуги }\end{array}$ & $\begin{array}{l}\text { Комплекс мер, направленных на } \\
\text { реализацию туристского про- } \\
\text { дукта (реклама, участие в спе- } \\
\text { циализированных выставках, } \\
\text { ярмарках, организация турист- } \\
\text { ских информационных центров, } \\
\text { издание каталогов, буклетов и } \\
\text { другое). }\end{array}$ & \\
\hline $\begin{array}{l}\text { Реализация } \\
\text { туристической } \\
\text { услуги }\end{array}$ & $\begin{array}{l}\text { Деятельность туроператора или } \\
\text { турагента по заключению дого- } \\
\text { вора о реализации туристского } \\
\text { продукта с туристом или иным } \\
\text { заказчиком туристского продук- } \\
\text { та, а также деятельность туро- } \\
\text { ператора и(или) третьих лиц по } \\
\text { оказанию туристу услуг в соот- } \\
\text { ветствии с данным договором. }\end{array}$ & $\begin{array}{l}\text { Деятельность туристических агентов, } \\
\text { направленная на повышение доступно- } \\
\text { сти реализации туристского продукта, } \\
\text { их реализация путем превращения по- } \\
\text { требителя в агента туристической услу- } \\
\text { ги. }\end{array}$ \\
\hline
\end{tabular}

движению и послепродажному обслуживанию инновационного туристского продукта субъектами инновационной деятельности в туризме, а также по финансовому обеспечению этих процессов, приводящих к получению экономического эффекта. В контексте данного исследования целесообразно использовать толкование процессов, входящих в состав инновационной деятельности в туризме на основе определений, взятых из Закона Украины «О туризме» (табл. 1) [3].

Инновационный процесс в туризме достаточно специфичен. Он получает свое признание, с одной стороны, через турист- ский рынок и степень удовлетворенности клиента, а с другой стороны, в основном, благодаря принятию совместных решений туристскими организациями, органами управления отраслью в регионе, органами местного самоуправления и общественными организациями, деятельность которых связана с туризмом, а также благодаря оценке отрасли местным населением.

Базируясь на положениях соглашения по торговле услугами (ГАТС), в туризме инновационная деятельность развивается по трем направлениям:

- внедрение нововведений (организа- 
ционные инновации), связанных с развитием предприятия и туристского бизнеса в системе и структуре управления;

- PR-инновации, позволяющие выделять растущие потребности целевых потребителей или привлекать не охваченных на данный период времени клиентов;

- периодические нововведения (продуктовые инновации), направленные на изменение потребительских свойств туристского продукта, его позиционирование и дающие конкурентные преимущества.

В. С. Новиковым проведена [13] классификация основных направлений инновационной деятельности в туризме в зависимости от технологических параметров (продуктовая инновация), внутреннего содержания (организационная и маркетинговая инновация), по принципу принадлежности направления к какому-либо виду инновации. Нами предлагается усилить данный подход для использования его в дальнейших исследованиях.

Рассмотрев предложенные различными авторами виды инноваций и их классификацию, мы выбрали классификацию, описанную в научных трудах А. И. Пригожина [15] и позволяющую достаточно широко описать основные направления инновационной деятельности в туризме. Автором классификация разбита на 5 групп:

1) по распространенности: единичные; диффузные;

2) по месту в производственном цикле: сырьевые; обеспечивающие (связывающие); продуктовые;

3) по преемственности: замещающие; отменяющие; возвратные; открывающие; ретровведения;

4) по охвату ожидаемой доли рынка: локальные; системные; стратегические;

5) по инновационному потенциалу и степени новизны: радикальные; комбинаторные; совершенствующие.

В рамках данного исследования для нас наибольший интерес представляет последнее направление классификации, учитывающие масштаб и новизну инноваций, интенсивность инновационного изменения в наибольшей степени выражают количественные и качественные характеристики инноваций в любой отрасли экономики и имеют значение для экономической оценки их последствий и обоснования управленческих решений.

Классификация видов инноваций А. Н. Кобышева является аналогом классификации, предложенной А. И. Пригожиным. В своей работе А. Н. Кобышев рассматривает результат инновационной деятельности в виде маркетинговой инновации, подразумевая приложение маркетинговых усилий в двух направлениях. На стадии маркетинга инновационной идеи существенно определение степени ее инновационного потенциала. По этому критерию инновации делятся на три типа: радикальные, комбинаторные, модифицирующие. Несколько иной подход к определению основных направлений инновационной деятельности в туризме в своих работах показал Г. А. Яковлев. По его мнению, основными направлениями инновационной деятельности туристских предприятий являются использование новой техники и технологий в оказании традиционных услуг, внедрение новых услуг с новыми свойствами, изменения в организации производства и потребления традиционных туристских услуг, вовлечение ранее не использованных туристских ресурсов, выявление и использование новых рынков сбыта туристских услуг и товаров. Г. А. Яковлевым не указано, по какому принципу проведена эта классификация [16].

Рассмотрев предложенные варианты, предлагается объединить и усилить подходы, принимая во внимание данное ранее определение экономической категории «инновационная деятельность в туризме» и рассмотреть основные направления инновационной деятельности в зависимости от того, к какому процессу они относятся (табл. 2).

Кроме того, предлагается структурировать основные направления инновационной деятельности в зависимости от того, к какому элементу они относятся (табл. 3).

Инновационные изменения в туризме создают внутреннюю энергию эффективного роста. Эти изменения нарушают сбалансированность, но создают основы дальнейшего развития, переход системы в новое качество. Поэтому именно профессиональное введение инноваций в жизнь и является развитием той или иной отрасли. Современные специалисты по развитию общества утверждают, что 
Таблица 2

Основные направления инновационной деятельности в туризме

\begin{tabular}{|c|c|c|c|}
\hline Вид инновации & Формирование & Продвижение & Реализация \\
\hline $\begin{array}{l}\text { Радикальные } \\
\text { (скачкообразные) }\end{array}$ & $\begin{array}{l}\text { Создание и использо- } \\
\text { вание при производ- } \\
\text { стве инновационных } \\
\text { продуктов и услуг } \\
\text { новых туристских } \\
\text { ресурсов и ранее не } \\
\text { использованных для } \\
\text { создания услуги. }\end{array}$ & $\begin{array}{l}\text { Изменение } \\
\text { понимания } \\
\text { туристического агента } \\
\text { и потребителя } \\
\text { туристической } \\
\text { услуги. }\end{array}$ & $\begin{array}{l}\text { Формирование } \\
\text { нового сегмента } \\
\text { рынка } \\
\text { комбинированных } \\
\text { агентов } \\
\text { (потребителей) - } \\
\text { лояльный клиент. }\end{array}$ \\
\hline $\begin{array}{l}\text { Комбинаторные } \\
\text { (объединяющие) }\end{array}$ & $\begin{array}{l}\text { Внедрение услуг с } \\
\text { новыми свойствами } \\
\text { в традиционный ту- } \\
\text { ристский продукт. } \\
\text { Инновация будет за- } \\
\text { ключаться в использо- } \\
\text { вании новых свойств } \\
\text { продукта для повы- } \\
\text { шения мотивации при } \\
\text { его разработке. }\end{array}$ & $\begin{array}{l}\text { Формирование } \\
\text { сегмента } \\
\text { продвижения } \\
\text { традиционных } \\
\text { туристских услуг } \\
\text { (табл. 1) с использова- } \\
\text { нием нового понима- } \\
\text { ния услуги для потре- } \\
\text { бителя. }\end{array}$ & $\begin{array}{l}\text { Поиск новых } \\
\text { сегментов рынка } \\
\text { туристических услуг } \\
\text { путем введения } \\
\text { новых услуг (напри- } \\
\text { мер, е-туризм). }\end{array}$ \\
\hline $\begin{array}{l}\text { Совершенствую- } \\
\text { щие (целевые) }\end{array}$ & $\begin{array}{l}\text { В рамках перехода от } \\
\text { традиционного спо- } \\
\text { соба ведения бизнеса } \\
\text { через радикальный } \\
\text { вид формирования де- } \\
\text { ятельности для пред- } \\
\text { приятия будет до- } \\
\text { ступно предвидение } \\
\text { потребностей клиента } \\
\text { в будущем периоде, } \\
\text { что и станет основой } \\
\text { для формирования ту- } \\
\text { ристической услуги. }\end{array}$ & \multicolumn{2}{|c|}{$\begin{array}{l}\text { При наличии «лояльных» клиентов, и в том } \\
\text { числе - клиентов-агентов, улучшение ор- } \\
\text { ганизации продвижения традиционных ту- } \\
\text { ристских услуг будет состоять в повышении } \\
\text { заинтересованности самих потребителей не } \\
\text { только воспользоваться физическими свойст- } \\
\text { вами услуги, но и купить данный продукт как } \\
\text { таковой. }\end{array}$} \\
\hline
\end{tabular}

ни одна из проблем, с которыми сталкивается в наши дни бизнес, не является более важной и сложной, чем проблема нововведений.

Инновации в туризме, естественно, влияют на состояние всей отрасли в целом. Они изменяют следующие основные характеристики отрасли:

- объем производства и продаж;

- текущие затраты фирмы, занимающейся инновациями;
- размер созданного и действующего имущества;

- численность специалистов, занятых в проектировке и внедрении нового туристического продукта на рынок;

- длительность освоения и внедрения новшеств потребителям.

К инновационной деятельности в туризме относится вся деятельность в рамках инновационного процесса, включая маркетинговые 
Таблица 3

Основные направления инновационной деятельности в туризме в зависимости от того, к какому элементу они относятся

\begin{tabular}{|c|c|}
\hline Элементы туризма & Направления инновационной деятельности \\
\hline Туристский продукт & $\begin{array}{l}\text { - выпуск новых видов туристского продукта; } \\
\text { - внедрение услуг с новыми свойствами в традиционный } \\
\text { туристский продукт; } \\
\text { - изменения в организации производства традиционных } \\
\text { туристских продуктов и т. д. }\end{array}$ \\
\hline $\begin{array}{l}\text { Субъект (физические } \\
\text { лица, общественные, } \\
\text { государственные } \\
\text { и частные предприятия } \\
\text { и организации туризма) }\end{array}$ & $\begin{array}{l}\text { - внедрение современных форм учета и отчетности; } \\
\text { - поддержка туризма и маркетинга через стимулирование } \\
\text { инноваций и кооперации; } \\
\text { — формирование привлекательного образа страны; } \\
\text { — прямое участие государства в реализации инновационных } \\
\text { программ; } \\
\text { - создание крупных инновационных центров; } \\
\text { - поддержка НИОКР в сфере туризма; } \\
\text { - создание венчурных инновационных фондов; } \\
\text { - создание сети технополисов, технопарков и т. п.; } \\
\text { — комплексные научные исследования в сфере туризма; } \\
\text { - совершенствование систем управления интеллектуальным } \\
\text { потенциалом субъектов отрасли; } \\
\text { - содействие обмену информацией, навыками и технология- } \\
\text { ми между развитыми и развивающимися странами и т. д. }\end{array}$ \\
\hline $\begin{array}{l}\text { Объект (все сферы, } \\
\text { связанные с туризмом) }\end{array}$ & $\begin{array}{l}\text { — производство инновационных продуктов и услуг; } \\
\text { - использование при производстве инновационных продук- } \\
\text { тов и услуг новых туристских ресурсов, ранее не использо- } \\
\text { ванных; } \\
\text { — обучение кадров для реализации и обновления их интел- } \\
\text { лектуального потенциала, технологической проработки про- } \\
\text { цесса обслуживания; } \\
\text { — использование новейших разработок и технологий и т. д. }\end{array}$ \\
\hline $\begin{array}{l}\text { Организатор } \\
\text { (юридическое лицо или } \\
\text { индивидуальный } \\
\text { предприниматель, } \\
\text { обеспечивающий } \\
\text { планирование } \\
\text { и осуществление } \\
\text { мероприятий, программ, } \\
\text { создание } \\
\text { и распространение } \\
\text { турпродукта) }\end{array}$ & $\begin{array}{l}\text { — деятельность туроператора по заключению и исполнению } \\
\text { договоров с третьими лицами, оказывающими отдельные но- } \\
\text { вые или усовершенствованные услуги, входящие в инноваци- } \\
\text { онный турпродукт; } \\
\text { — организация рекламы и сбыта инновационного туристского } \\
\text { продукта (участие в специальных выставках, ярмарках, орга- } \\
\text { низация туристских информационных центров и пр.); } \\
\text { - сохранение и усиление рыночных позиций; } \\
\text { — совершенствование системы управления, способствующее } \\
\text { переводу взаимоотношений на качественного новый уровень; } \\
\text { - углубленное использование телекоммуникаций, создание и } \\
\text { обработка баз данных и т. д. }\end{array}$ \\
\hline Участник & $\begin{array}{l}\text { - выявление и использование нового потребителя и нового } \\
\text { рынка сбыта туруслуг и т. д. }\end{array}$ \\
\hline
\end{tabular}


исследования рынков сбыта и поиск новых потребителей, информационное обеспечение возможной конкурентной среды и потребительских свойств товаров конкурирующих фирм, поиск новаторских идей и решений, партнеров по внедрению и финансированию инновационного проекта, а также совершенствование системы управления характером и структурой взаимоотношений субъектов отрасли, формирования их интеллектуального потенциала.

На развитие инновационной деятельности туристских компаний оказывают влияние следующие факторы:

- экономические и технологические (отсутствие достаточных средств для финансирования, слабость материально-технической базы, устаревшая технология);

- политические, правовые (политическая нестабильность, криминогенная обстановка, ограничения, вводимые законодательным путем);

- организационно-управленческие (излишняя централизация, ориентация на краткосрочную окупаемость, сложность согласования интересов участников инновационных процессов, преобладание вертикальных потоков информации);

- социально-психологические и культурные (сопротивление новшествам, всему новому, что поступает извне, боязнь неопределенности).

Все эти факторы зависят от состояния внешней и внутренней среды, анализ которой при организации инновационной деятельности в туристской компании должен быть постоянно в центре внимания.

При анализе состояния внешней среды особое внимание следует обращать на факторы, которые непосредственно влияют на внедрение инноваций. Это:

- общая экономическая ситуация, под воздействием которой формируются покупательский спрос и платежеспособность населения;

- действия исполнительных органов власти по поддержке развития туризма, требования законодательного и регулирующего характера как общегосударственного, так и регионального значения, касающиеся туризма;
- интенсивность и масштаб конкуренции;

- состояние коммуникационных сетей (возможности использования Интернета, других альтернативных способов связи);

- возможность применения новых технологий при организации поездок (глобальные системы бронирования субъектами туристского рынка, число компаний, применяющих новые технологии, особенно в регионах);

- период времени, требующийся для продвижения новинок компьютерных технологий и новых предложений на региональных рынках.

Кроме факторов внешней среды, сдерживающих инновационные процессы в развитии туристского бизнеса, многое зависит от внутренней среды. К факторам внутренней среды относятся: политика и стратегия туристской компании; наличие в коллективе работника-инициатора; безоговорочная поддержка инновационных идей со стороны руководства; всемерное содействие экспериментам на всех уровнях и во всех подразделениях туристской компании; использование мотивационных систем, включающих различные формы поощрения творческой и инновационной деятельности; наличие специализированного подразделения по реализации новшеств; необходимый уровень финансовых возможностей; развитые коммуникационные системы; организационно-техническая готовность к реализации новшества, четко спланированная система управления персоналом, в том числе интеллектуальным потенциалом сотрудников.

Инновации в туризме представляются средством высокой степени сложности. Они, как правило, реализуются посредством серии мелких шагов, которые ведут к постепенному развитию и являются процессом с обратной связью. Одна инновация неизбежно влечет за собой другую.

В передовых туристских компаниях инновации являются рутинным делом. Уже не ставится вопрос о счастливой случайности или внезапном проявлении гения - инновации программируются предприятием и являются стандартной составляющей корпоративного принятия решения о распределении 
ресурсов. Современные компании резервируют значительную часть своего общего бюджета на исследования и развитие и сделали инновации частью ежедневного планирования. Инновации становятся предсказуемым и контролируемым бюрократическим процессом, который сейчас является объективным дополнительным фактором производства.

В современном понимании инновации в туризме - это планируемые, целенаправленные, неизбежные, управляемые и практические изменения и нововведения на уровне организаций, задействованных в туристической сфере, общественных объединений и государств, направленные на развитие туристических потоков и создание предложения, максимально удовлетворяющего и опережающего индивидуальный спрос.

Все компоненты сферы туризма должны подвергаться влиянию научно-технического прогресса. Только такое взаимодействие всех элементов сферы туризма может привести к появлению существенного синергетического эффекта, выраженного в качестве роста сферы туризма. В итоге выигрывает тот, кто раньше всех придает своему туристскому продукту новые потребительские качества и свойства и умеет заинтересовать потребителя этими новациями.

Таким образом, особенностью развития инновационной деятельности в туризме является создание нового или изменение существующего продукта, совершенствование транспортных, гостиничных и других услуг, освоение новых рынков, внедрение передовых информационных и телекоммуникационных технологий и современных форм организационно-управленческой деятельности.

\section{Литература}

1. Азгальдов Г. Г., Костин А. В. Интеллектуальная собственность, инновации и квалиметрия. // Экономические стратегии. - 2008. — №2. [Электронный ресурс] / Библиотека оценщика Labrate.ru. - Режим доступа: http://www.labrate.ru/articles/azgaldovkostin_doklad_2009-2_about-innovation.htm, свободный. - Загл. с экрана.

2. Федеральный Закон Российской Федерации «Об основах туристической деятельности» от 24 ноября 1999 года с поправками и изменениями. [Электронный ресурс] / Информационно-правовой портал «Гарант». Режим доступа: http://www.garant.ru/, свободный. - Загл. с экрана.

3. Закон Украины «О туризме» в редакции от 18.11.03 №1282-IV. // BBP. - 2003 г.

4. Бешелев С. Д. Математико-статистические методы экспертных оценок. 2-е изд., перераб. и доп. / С. Д. Бешелев, Ф. Г. Гурвич. - М.: Статистика, 1980. - 263 с.

5. Брайан T. Управление научно-техническими нововведениями. - М.: Экономика, 1989. $-310 \mathrm{c}$.

6. Друкер П. Инновации и предпринимательство. - СПб.: Бук Чембер Интернешнл, 1992. - $536 \mathrm{c}$.

7. Канторович Л. В. Инновационные механизмы функционирования предпринимательских систем. - М.: РЭА им. Г. В. Плеханова, 2001. - $113 \mathrm{c}$.

8. Лапин Н. И. Теория и практика инноватики: учебное пособие. - М.: Логос, 2010. $-328 \mathrm{c}$.

9. Медынский $B$. Г. Инновационное предпринимательство: учебное пособие. / В. Г. Медынский, Л. Г. Шаршукова. - М.: ИНФРА-М, 1997. — 237 с.

10. Молчанов И. Н. Инновационный процесс. - СПб.: Изд-во Санкт-Петербургского ун-та, 1995. - $143 \mathrm{c}$.

11. Никсон $\Phi$. Инновационный менеджмент. - М.: Экономика, 1997. - 356 с.

12. Санто Б. Инновация как средство экономического развития. / Пер. с венг. - М.: Прогресс, 1990. - 263 с.

13. Новиков В. C. Инновации в туризме. - М.: Академия, 2007. - 315 с.

14. Новиков В. С. Характерные черты туризма XXI века - устойчивое и инновационное развитие. // Сборник научных статей (10 выпуск) Московской академии туристского и гостинично-ресторанного бизнеса при правительстве Москвы. - М., 2011. - С. 25-29.

15. Пригожин А. И. Нововведения: стимулы и препятствия (социальные проблемы инноватики). - М.: Наука, 2010. - 220 с.

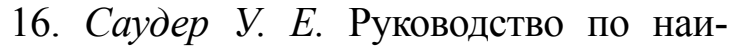
лучшим методам трансфера технологий. / У. Е. Саудер, А. С. Нашар. // Управление инновациями. - М.: Дело-ЛТД, 2005. - 318 с.

17. Шумпетер Й. Теория экономического развития (исследование предприниматель- 
ской прибыли, капитала, кредита, процента и цикла конъюнктуры). / Пер. с англ. - М.: Прогресс, 1982. - 455 с.

18. Яковлев $Г$. А. Основные направления инновационной деятельности в туриз- ме. [Электронный ресурс] / Scientific World. - Режим доступа: http://www.sworld.com. ua/index.php/en/economy-311/innovationeconomy-311/7693-main-areas-of-innovationin-tourism, свободный. - Загл. с экрана.

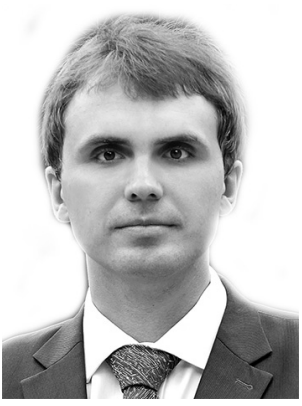

Юрий Юрьевич Швец - кандидат экономических наук, старший научный сотрудник лаборатории экономической динамики и управления инновациями Института проблем управления РАН. Автор более 70 опубликованных научных работ. Области научных интересов: инновации на отраслевых рынках, региональная экономика, экономика образования.

Yuriy Yurievich Shvets - Ph.D., Candidate of Economics, senior research officer at the Laboratory of Economic Dynamics and Control for the Innovations of the RAS Institute for Control Studies. Author of more than 70 scientific publications. Majors in the innovations at local markets, regional economy, economics of the education.

117997, Москва, ул. Профсоюзная, 65, ИПУ РАН, лаб. 67 65 Profsoyuznaya st., RAS ICS, lab. 67, 117997, Moscow, Russia

Тел.: +7 (495) 334-89-10; e-mail: jurijswets@yahoo.com 